\title{
A CASE OF CAVERNOUS SINUS THROMBOSIS OF OTITIC ORIGIN BY SUPPOSED DIRECT INFEC- TION OF THE PETROSAL SINUSES.
}

\author{
By J. A. M. HEMmEON, M.D., C.M., F.A.C.S., Halifax, N.S.
}

APOLOGY must be offered at the outset for the absence of laboratory and post-mortem findings in this case. It is realised that these defects make the case of small authoritative value, but it must, nevertheless, be of interest if only for its unusual clinical features. It must be borne in mind that the case occurred in a district far from hospital and laboratory facilities.

Thrombosis of the cavernous sinus is a comparatively rare condition, and is dismissed in most modern text-books in a few lines. It is looked upon as an inoperable condition, though several routes for reaching the sinus have been suggested. It is, admittedly, generally fatal, though a few spontaneous recoveries have been noted. M'Kenzie, ${ }^{1}$ in his recent book, says that it "is an uncommon sequel of lateral sinus thrombosis, and indeed is more frequently due to nasal, pharyngeal and facial infections than to aural infections."

Ballenger " says that it "is rare, and when of otitic origin usually extends from the superior or inferior petrosal sinuses." This author surely means to imply that the infection of the petrosal sinuses is usually through the lateral sinus. He cites three cases, and the first appears to be a direct infection of the petrosal sinuses. But, in this case, "mastoid symptoms developed rapidly," and the lateral sinus was opened though not found thrombosed. Death occurred on the seventh day. Ballenger ${ }^{3}$ further says, "the condition usually begins in one sinus and spreads to the other through the circular sinus." So, as one goes through the text-books, one finds the condition almost invariably referred to in connection with lateral sinus thrombosis.

Rodger ${ }^{4}$ reports a series of cases, in one of which he thinks he has evidence of primary infection and thrombosis of the petrosal sinuses, following acute otitis media of some weeks' standing. In his case, following a facial paralysis, the radical mastoid operation was done, the lateral sinus exposed and no clot found. Two weeks later, signs of cavernous sinus thrombosis appeared and the lateral sinus was again opened. A clot was vol. XXXvir, No. vi. 


\section{J. A. M. Hemmeon}

evacuated and, following a gush of blood, two small, worm-like, septic clots were washed from the torcular end of the sinus. These, Rodger believes, to have come from the petrosal sinuses and that they were infected directly from the middle ear, the mastoid being found free from pus. The petrosal sinuses, lying on the pyramid of the petrous portion of the temporal bone, receive blood from the inferior cerebral and superior cerebellar veins and small branches from the tympanum. Many of these pass through the petro-squamosal suture, the remainder passing directly through the bone to the sinus. One can see how these sinuses may be directly infected through these small veins leading directly from the infected tympanum in acute purulent otitis media. I have not been able to find any further record of such direct infection, though there are almost daily reports of cases of infection through thrombosis of the lateral sinus and accompanying or following the well-known symptoms of that condition. Rodger ${ }^{5}$ says that he is unable to find any record of another such case. Circulation between the cavernous sinuses is so free, through the circular sinus, that thrombosis of both sinuses, rather than of one only, is the rule.

Maybaum ${ }^{6}$ says that the prognosis in this condition is quite hopeless. Suggested operative measures aim at reaching the sinus to clear out the clot.

Dwight ${ }^{7}$ suggests turning down a bone flap as in the Krause operation for exposure of the Gasserian ganglion. More recently a route through the nose and sphenoidal sinuses has been suggested. Up to the present, results of operation are discouraging, and cases are usually treated conservatively after the lateral sinus has been explored.

Dwight ${ }^{8}$ reports 14 cases of spontaneous recovery. Many cases of cavernous sinus thrombosis following infection of the frontal, ethmoidal and sphenoidal sinuses, as well as of the orbit, have been reported.

Kernan ${ }^{9}$ presents an unusual case following peri-tonsillar abscess. In this case, the abscess being twice ineffectively incised, a thrombus involved the internal jugular vein and the sigmoid, petrosal and cavernous sinuses.

Müller ${ }^{10}$ reports a case of primary thrombosis of the superior petrosal sinus, discovered while exposing the lateral sinus following mastoidectomy.

The clinical picture in cavernous sinus thrombosis is quite distinctive. There is oedema and discoloration of both lids, 


\section{Cavernous Sinus Thrombosis}

bulging and immobility of the eyeball, chemosis of the ocular conjunctiva with rapidly failing vision and characteristic excessive temperature elevation with, in some cases, marked remissions.

"The temperature is a less reliable guide in the child than in the adult and may be steadily high rather than remittent."-OPPENHEIM. ${ }^{11}$

Case Report.-The case was seen and reported through the courtesy of Dr Elliott of Wolfville, N.S., who contributes the history to I 7 th September $192 \mathrm{I}$.

Henry N., aged 5 years. Past History.-No illness except "Influenza" in 19ı8. Tendency to "Colds in head" during $192 \mathrm{r}$.

Present Illness. - Rhinitis noticed 9th Sept. I Ith Sept.-Complained of pain in left ear. First seen by Dr Elliott at noon. I2th Sept.-Pain in left ear persisting. Temp. Iоr. $5^{\circ}$. Left M.T. bulging. Left M.T. incised-Free flow of blood and pus. Pain persisted through night. ${ }^{5}$ th $^{\text {th Sept.-Temp. 102.6 }}{ }^{\circ}$. Patient dull, refuses nourishment. Left ear discharging freely. Physical examination otherwise negative. I6th Sept.-Temp. 103.6 $6^{\circ}$ : pulse 120. Patient dull, answers questions. Free discharge from left ear. Beginning cedema of left upper lid. I 7 th Sept.-Temp. 103.8 ; pulse 120. CEdema of both lids noticed in the morning.

The child was first seen by the writer at 9 P.M. Temp. $104^{\circ}$ per rectum. No history of rigors. Pulse $\mathbf{1} 20$. Patient unconscious but can be roused with difficulty. Face pale, skin moist, tongue coated. Abdomen and chest negative. Kernig and Babinski signs absent. Profuse foul smelling purulent discharge from left ear. When this is wiped away the M.T. is seen somewhat bulging with an incision in the posterior superior quadrant. A smear made from the pus was unfortunately lost. Head somewhat retracted but no rigidity of neck. No swelling, redness, or tenderness in the peri-auricular tissues or in the neck. There is tenderness over the entire scalp. Right M.T. somewhat red, not bulging. Pupils equal, moderately dilated, and reacting sluggishly to light. No conjugate deviation of the eyes. Some cedema of the lids noted with pale bluish discoloration. Considerable bulging of the eyeballs with ptosis and chemosis of ocular conjunctiva. Both eyes equally affected. Incontinence of urine.

A diagnosis of cavernous sinus thrombosis was made. There were no signs of mastoid involvement that might have led to lateral sinus thrombosis, consequently an operation for exposure of the lateral sinus was not advised. I 8th Sept.-Seen at 3 P.M.; pulse 130, regular, moderately strong. Temp. $104.5^{\circ}$ per rectum. Head greatly retracted. Neck somewhat rigid. Kernig's sign slightly manifest. Babinski 


\section{J. A. M. Hemmeon}

negative. Patient utters short sharp cry at intervals and is very restless. Patient is unconscious and cannot be roused. Incontinence of urine and fæces. All ocular symptoms are increased. Marked cedema of lids with immobility and bulging of eyeballs and ptosis. Chemosis of conjunctiva. Pupils moderately dilated and react sluggishly to light. No conjugate deviation. Right tympanic membrane shows bulging. It was decided to incise this membrane and to enlarge the incision in the left membrane though drainage appeared good from this ear. Under light chloroform anæsthesia this was done, incision in the left drum revealing a mucopurulent secretion in the left middle ear.

At this time a lumbar puncture was made and 5 c.c. of clear fluid under moderately increased pressure were withdrawn. The amount of anæsthetic given was small and neither pulse nor respirations were affected during the anæsthesia. The patient was more quiet until the effects of the anæsthetic wore off. Later, increased restlessness with weakening pulse. Patient died quietly at I I P.M. No rigors. No convulsive movements. No post-mortem examination was made.

Laboratory Report on examination of Cerebro-spinal Fluid - "Specimen of spinal fluid. Smear negative. Culture negative-sterile. Polymorphs, 64 per cent."

References.-1' Dan M'Kenzie, Diseases of Throat, Nose, and Ear, I921, p. 542. ${ }^{2}$ Ballenger, Diseases of Nose, Throat, and Ear. ${ }^{3}$ Ibid. ${ }_{4} \mathrm{~T}$. Ritchie Rodger, Journal of Laryngology and Otology, vol. xxxvi. No. 4. ${ }^{5}$ lbid. ${ }^{6}$ Maybaum, The Laryngoscope, vol. xxxi. No. 4. ${ }^{7}$ Dwight and Germain, Boston Medical Journal, I920. ${ }^{8}$ Ibid. 9 Kernan, The Laryngoscope, vol. xxx. No. 4. ${ }^{10}$ Müller, Zeitschr.f. Ohrenh., 1920. 11 Oppenheim, Archives of Pedriatics, 1920. 